\title{
The emergence, development and regional differences of mixed farming of rice and millet in the upper and middle Huai River Valley, China
}

\author{
YANG YuZhang ${ }^{1}$, CHENG ZhiJie ${ }^{1}$, LI WeiYa ${ }^{1,2}$, YAO Ling ${ }^{1}$, LI ZhanYang ${ }^{3}$, \\ LUO WuHong $^{1 *}$, YUAN ZengJian ${ }^{1}$, ZHANG Juan $^{1} \&$ ZHANG JuZhong ${ }^{1 \dagger}$ \\ ${ }^{1}$ Department for the History of Science and Scientific Archaeology, University of Science and Technology of China, Hefei 230026, China; \\ ${ }^{2}$ Faculty of Archaeology, Leiden University, Leiden 2333CC, the Netherlands; \\ ${ }^{3}$ Henan Provincial Institute of Cultural Relics and Archaeology, Zhengzhou 450000, China
}

\begin{abstract}
Mixed farming of rice and millet is one of the basic agricultural modes in the upper and middle Huai River Valley (HRV). According to the latest data, this agricultural mode appeared during the middle and late Peiligang Culture (7.8-7.0 ka $\mathrm{BP}$ ) in the upper HRV, and then became a common subsistence economy in the end of the Neolithic (5.0-4.0 ka BP) in both the upper and middle HRV. However, it is still not clear how this mixed farming developed in the upper HRV after its occurrence, nor are the regional differences in the development of mixed farming between the upper and middle HRV during the Neolithic completely understood. In this paper, flotation and starch analyses were conducted on samples from eight archaeological sites in the upper and middle HRV. The results indicate that the mixed farming of rice and millet first appeared in the later phase of the middle Neolithic in the regions of the Peiligang Culture, then developed quite rapidly in the late Neolithic (6.8-5.0 ka BP), finally becoming the main subsistence economy at the end of the Neolithic in the upper HRV. However, there are obvious differences in the emergence and development of agriculture between the middle and upper HRV. Rice farming was the only agricultural system during the middle Neolithic, lasting until the end of the Neolithic, when mixed farming appeared in the middle HRV. Furthermore, although mixed farming appeared in both the upper and middle HRV during the end of the Neolithic, the roles of rice, foxtail millet and broomcorn millet in the subsistence economy were not the same. In general, millet was more widely cultivated than rice in the upper HRV, but rice occupied the same or a slightly more prominent position in the middle HRV at the end of the Neolithic. These results are significant for understanding the process of agricultural development and transformation, as well as human adaptation to climatic and cultural variability duringthe Neolithic.
\end{abstract}

Keywords Upper and middle Huai River, Neolithic, Mixed farming of rice and millet, Agricultural development and transformation, Regional differences

Citation: $\quad$ Yang Y Z, Cheng Z J, Li W Y, Yao L, Li Z Y, Luo W H, Yuan Z J, Zhang J, Zhang J Z. 2016. The emergence, development and regional differences of mixed farming of rice and millet in the upper and middle Huai River Valley, China. Science China Earth Sciences, 59: 1779-1790, doi: 10.1007/s11430-015-5340-3

*Corresponding author (email: wh0551@mail.ustc.edu.cn)

†Corresponding author (email: juzhzh@ustc.edu.cn) 


\section{Introduction}

Agriculture was one of the main driving forces behind the growth of civilization and early social progress (Childe, 1951; Yan, 2000; Bar-Yosef, 2011), and so its origin and development have long attracted attention in the international academic community. China is one of the three major centers in the world for the origin of agriculture, with northern China and the mid-lower Yangtze river regions being widely considered as the respective birthplaces of millet and rice farming. Recent studies have shown that domestication of rice and millet first occurred in southern and northern China, respectively, at approximately the same time, possibly about 11.5 ka BP (Zhao et al., 1998; Lu et al., 2009; Yang et al., 2012; Wu et al., 2014).

The upper and middle Huai River Valley (HRV), situated between the Yangtze and Yellow Rivers, is a transitional zone for climate and agriculture in eastern China and is the core area for cultural exchange and integration between northern and southern China. In terms of the distribution of crops in this area, the presence of mixed farming of rice and millet is one of the most remarkable features (Zhang et al., 2004). According to the earliest archaeobotanical data, mixed farming of rice and millet had already appeared during the middle and late Peiligang Culture (7.8-7.0 ka BP) and lasted until the period of the Longshan Culture in the upper HRV (Zhao and Fang, 2007; Liu et al., 2010; Zhang et al., 2012). In the middle HRV, there was mixed farming at the Yuchisi site in Mengcheng County toward the end of the Neolithic (Wang and Wu, 1998; Zhao, 2010). Nevertheless, there are still some open questions regarding the development progress of mixed farming after its appearance in the upper HRV and the regional differences that occurred in the development of mixed farming between the upper and middle HRV throughout the Neolithic.
In this study, flotation and starch grain analyses were applied to recover ancient plant remains from eight Neolithic sites. In addition, quantitative and frequency analyses were conducted on the archaeobotanical results from the eight sites, as well as on existing data in different phases of the Neolithic in the upper and middle HRV. The aim of this paper is to present information to allow better understanding of the history of prehistoric agricultural practices and the relationships among changing climate, archaeological cultures and human adaptation.

\section{Profiles of archaeological sites and research region}

According to previous studies, the Neolithic culture in the upper and middle HRV can be divided into four different phases: the early Neolithic (11.5-9.0 ka BP), the middle Neolithic (9.0-6.8 ka BP), the late Neolithic (6.8-5.0 ka $\mathrm{BP}$ ) and the end of the Neolithic (5.0-4.0 ka BP) (Zhang, 2005; Luan, 2005; Gao, 2005). The eight archaeological sites distributed over the research areas were at Lingjing, Jiahu, Shunshanji, Agangsi, Hunanguo, Lingyuntai, Sigeda and Yangpu (Figure 1). These sites are associated with the main Neolithic archaeological cultures in the upper and middle HRV. However, the development of agriculture during the late Neolithic in the middle HRV is not discussed here because of the limited amount of data available from only a few archaeological sites.

The upper and middle HRV covers the east central Henan, north central Anhui and northwest Jiangsu Provinces. The climate of the southern part of the HRV is humid subtropical and is strongly influenced by the East Asian monsoon. The mean annual temperature is over $15^{\circ} \mathrm{C}$, the annual average precipitation is around 1000-1200 $\mathrm{mm}$ and the

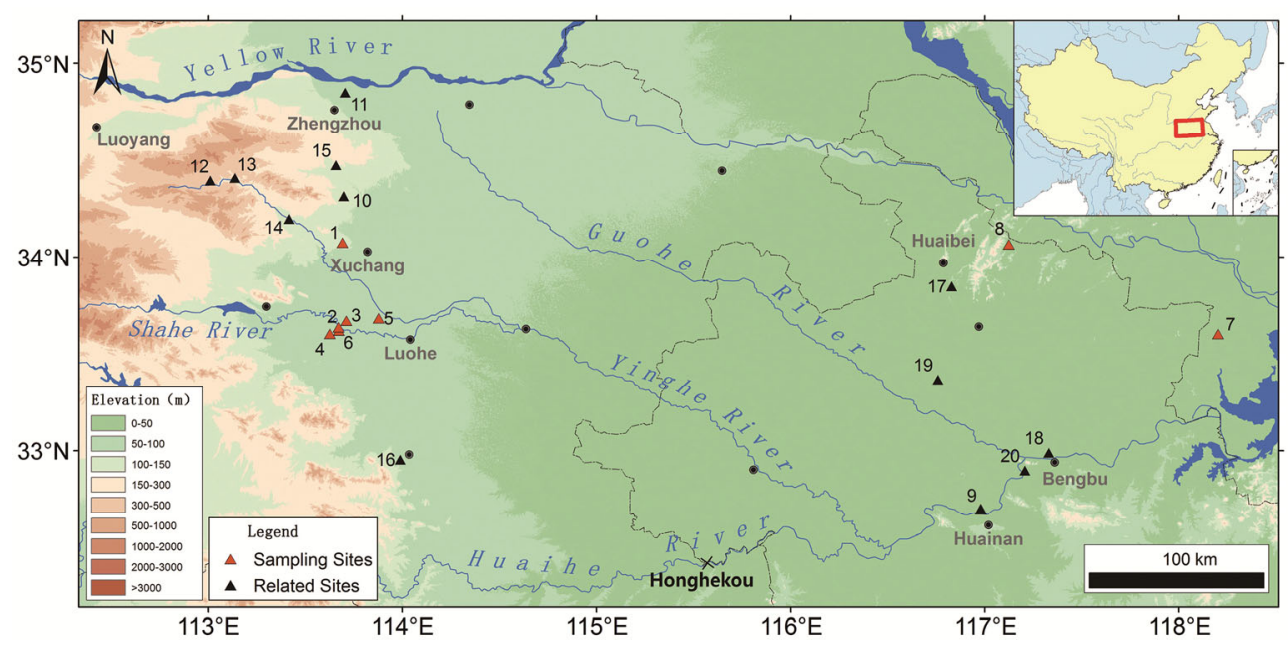

Figure 1 Locations of the eight sampling sites and related archaeological sites in the upper and middle HRV. 1, Lingjing; 2, Jiahu; 3, Hunanguo; 4, Agangsi; 5, Lingyuntai; 6, Sigeda; 7, Shunshanji; 8, Yangpu; 9, Xiaosungang; 10, Tanghu; 11, Dahecun; 12, Yuanqiao; 13, Wangchenggang; 14, Wadian; 15, Guchengzhai; 16, Yangzhuang; 17, Shishanzi; 18, Shuangdun; 19, Yuchisi; 20, Yuhui. 
average frost-free period surpasses 220 days. The main cultivated crops include rice, wheat and rape. The climate of the region to the north of the upper and middle HRV, where the broad Huanghuai Plain is located, is warm-temperate and semi-humid. The annual average temperature is more than $14^{\circ} \mathrm{C}$, the annual precipitation is about $800-900 \mathrm{~mm}$, the frost-free period is about 220 days and the staple crops include wheat, corn, cotton and soybean (Meteorological Bureau of Henan Province, 1980; Meteorological Bureau of Anhui Province, 1983).

\section{Materials and methods}

Eight archaeological sites distributed over the upper and middle HRV and dating to different periods of the Neolithic were chosen for archaeobotanical analysis. The chronologies from the Lingjing, Jiahu and Shunshanji sites have been reported previously (Henan Provincial Institute of Cultural Relics and Archaeology, 1999; Lin et al., 2014; Li et al., 2014), and the ages of the other five sites were obtained from the dates of plant remains from each site performed at the Center for Applied Isotope Studies, University of Georgia (Table 1). Flotation analysis was conducted on soil samples collected from the Jiahu, Yangpu, Agangsi, Hunanguo, Lingyuntai and Sigeda sites, and starch analysis was carried out on stone artifacts and pottery shards from the Lingjing and Shunshanji sites.

A froth-flotation device with a $0.2 \mathrm{~mm}$ mesh screen for light-fraction samples and $1.00 \mathrm{~mm}$ for the heavy fraction was used. The recovered carbonized plant remains were identified by comparison with modern and carbonized plant specimens from the Bioarchaeology Laboratory at the University of Science and Technology of China and related published documents(Guan, 2000; Guo, 1998; Shida et al., 2004).

For starch grain analysis, residue samples were collected from the used surfaces of stone tools and the internal sides of pottery shards by reverse osmosis water rinsing and ultrasonic procedure. Samples from the unused surfaces of stone tools and external sides of pottery shards were also collected as controls. Then, $5 \%\left(\mathrm{NaPO}_{3}\right)_{n}$ and $10 \% \mathrm{HCl}$ were added for deflocculation and to remove carbonates from the samples. Heavy liquid ( $\mathrm{CsCl}$ solution) with a relative density of 1.8 was then used for the extraction of starch grains. Identification of starch grains was conducted according to modern references and previous related publications (Piperno et al., 2004; Torrence and Barton, 2006; Wei et al., 2008; Yang et al., 2009; Yang et al., 2010; Ge et al., 2010; Perry and Michael, 2011; Wan et al., 2011; Yang and Perry, 2013; Liu et al., 2013, 2014a, 2014b).

\section{Results and analysis}

\subsection{Plant remains from the early Neolithic (before 9.0 ka BP)}

The surfaces of ten stone tool fragments and eight pottery shards unearthed from the fifth layer (14.0-11.0 ka BP) of the Lingjingsite yielded 39 starch grains that were classified into seven types on the basis of morphology and size. Of these, 36 grains were identified as coming from roots of snakegourd (Trichosantheskirilowii), Coix lacryma-jobi and Sagittaria trifolia, while the other 3 types of grains were difficult to classify (Figure 2). It could be seen that the species identified were wild and would normally have been obtained through gathering.

\subsection{Plant remains from the middle Neolithic (9.0- $6.8 \mathrm{ka} \mathrm{BP})$}

Plant remains from the middle Neolithic came from the Jiahu and Shunshanji sites, located in the upper and middle HRV, respectively. A total of 6300 charred plant remains were found from the archaeological contexts in phase II of the Jiahu Culture (ca. 8.5-8.0 ka BP), including Oryza sativa, Glycine soja, Vitis, Trapa, Quercus, Nelumbo nucifern, Caryacathayensis, and weedy seeds such as Chenopodiaceae, Amaranthaceae and Portulacaceae (Figure 3). It is worth noting that frequency analysis showed that the occurrence frequencies of edible plants obtained by gathering, such as Glycine soja, Vitis and Trapa, were greater than that of

Table 1 Ages and samples of the eight sites

\begin{tabular}{|c|c|c|c|c|c|}
\hline Site & Location & Age (ka BP) & Sample source & Sample type & Analysis method \\
\hline Lingjing (the fifth layer) & Xuchang, Henan & $14.0-11.0$ & Excavation & Pottery and stone tools & Starch analysis \\
\hline Jiahu & Wuyang, Henan & $9.0-7.5$ & Excavation & Soils & Floatation \\
\hline Shunshanji & Sihong, Jiangsu & $8.5-7.0$ & Excavation & Pottery and stone tools & Starch analysis \\
\hline Agangsi & Wuyang, Henan & $5.4-5.1$ & Survey & Soils & Floatation \\
\hline Hunanguo & Wuyang, Henan & $5.7-5.0$ & Survey & Soils & Floatation \\
\hline Yangpu & Suzhou, Anhui & End of Neolithic & Excavation & Soils & Floatation \\
\hline Lingyuntai & Luohe, Henan & $4.0-3.9$ & Survey & Soils & Floatation \\
\hline Sigeda & Wuyang, Henan & $4.2-4.1$ & Survey & Soils & Floatation \\
\hline
\end{tabular}




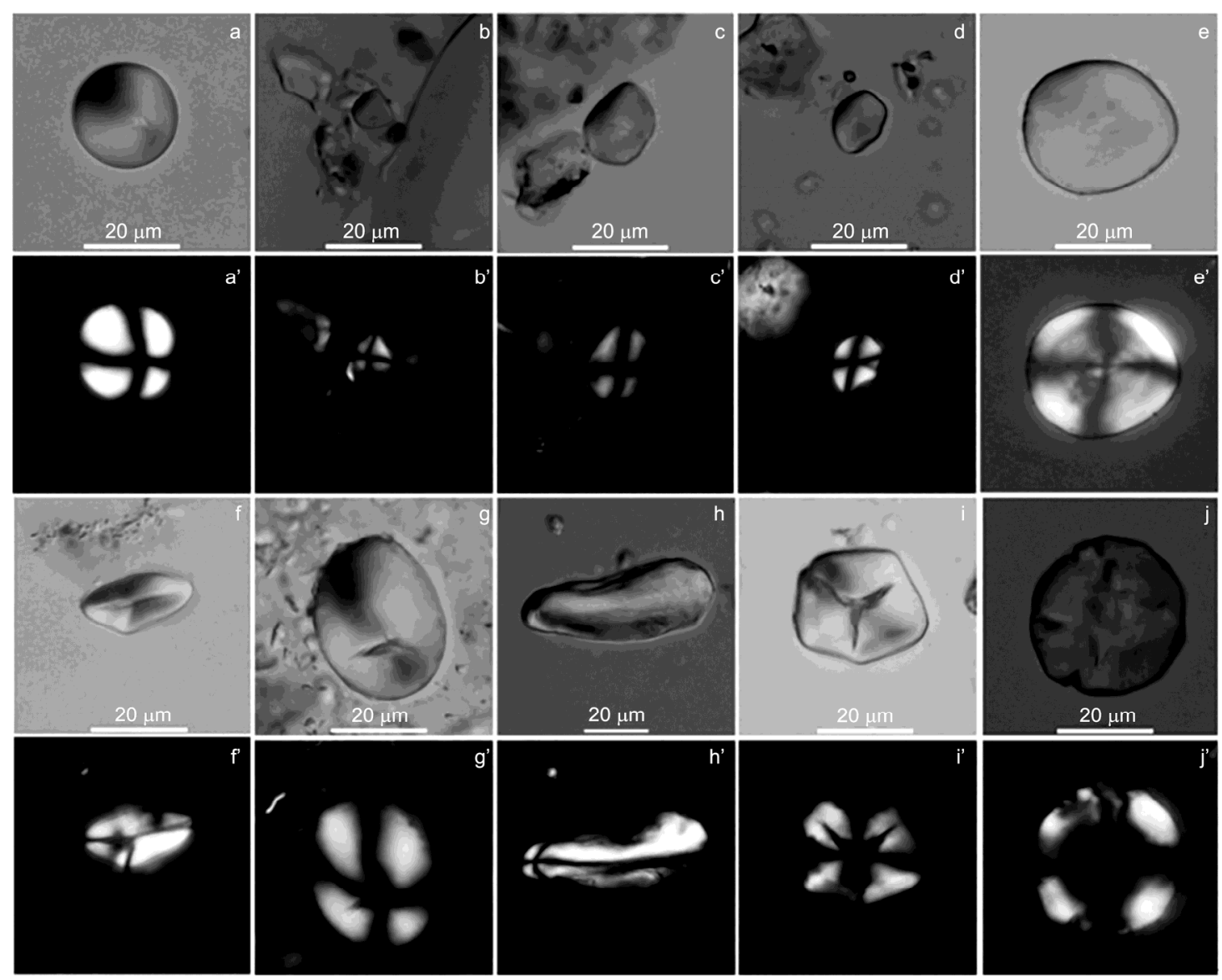

Figure 2 Ancient starch grains from the Lingjing site. (a), (a'), (b), (b'), Trichosanthes kirilowii; (c), (c'), (d), (d'), Coix lacryma-jobi; (e), (e'), (f), (f'), Triticeae; $(\mathrm{g}),\left(\mathrm{g}^{\prime}\right)$, Sagittaria trifolia; $(\mathrm{h}),\left(\mathrm{h}^{\prime}\right),(\mathrm{i}),\left(\mathrm{i}^{\prime}\right)$, unidentified species; $(\mathrm{j}),\left(\mathrm{j}^{\prime}\right)$, damaged starches.

Oryza sativa (Figure 3), suggesting that the ancient population at Jiahu largely relied on gathering to obtain plant foods.

At the Shunshanji site (8.5-7.0 ka BP), 414 ancient starches from Coix lacryma-jobi, Triticeae, Oryza sativa, Trichosanthes kirilowii and 1unidentified species were recovered from the surfaces of 17 stone tools and 29 cauldron pottery shards (Figure 4). The results demonstrated that although cultivation of rice might have taken place at Shunshanji, the ancient population still relied more on gathering to obtain plant foods.

\subsection{Plant remains from the late Neolithic (6.8-5.0 ka BP)}

The archaeobotanical evidence from the late Neolithic was obtained from the Hunanguo and Agangsi sites in the upper HRV. Here, 3701 charred plant remains were recovered. Qualitative analysis indicated that agricultural crops included foxtail millet, broomcorn millet and rice, wild grass seeds included Setaria, Digitaria and Echinochloa, and a few wild edible plants such as Quercus, Vitis and Diospyros were also found (Figure 5).The occurrence frequencies of millet and rice were the highest, followed by Setaria and Digitaria. The frequencies of other plants such as Quercus and Diospyros were below $10 \%$.

\subsection{Plant remains from the end of the Neolithic (5.0- 4.0 ka BP)}

Plant remains from the end of the Neolithic came from the Lingyuntai, Sigeda and Yangpu sites (Figure 6). The first two sites are located in the upper HRV and the third in the middle HRV. A total of 497 charred plant remains were recovered from the Lingyuntai and Sigeda sites, including crops such as foxtail millet, broomcorn millet, rice, and soybean, as well as some weed seeds like Setaria and Echinochloa. Statistical analysis results showed that the occurrence frequency of foxtail millet was the highest among all plant remains, followed by broomcorn millet, while the lowest frequency was that of rice. Notably, abundant charred soybean seeds were found at the Lingyutai site, although whether they were cultivated or wild is still unknown.

The Yangpusite covered the periods of the late Dawenkou Culture, the Longshan Culture, the Yueshi Culture, the Warring States and the Han Dynasty. A total of 660 charred plant remains were recovered from the relics from the late Dawenkou Culture and the Longshan Culture, including foxtail millet, broomcorn millet, rice and a few weed seeds 

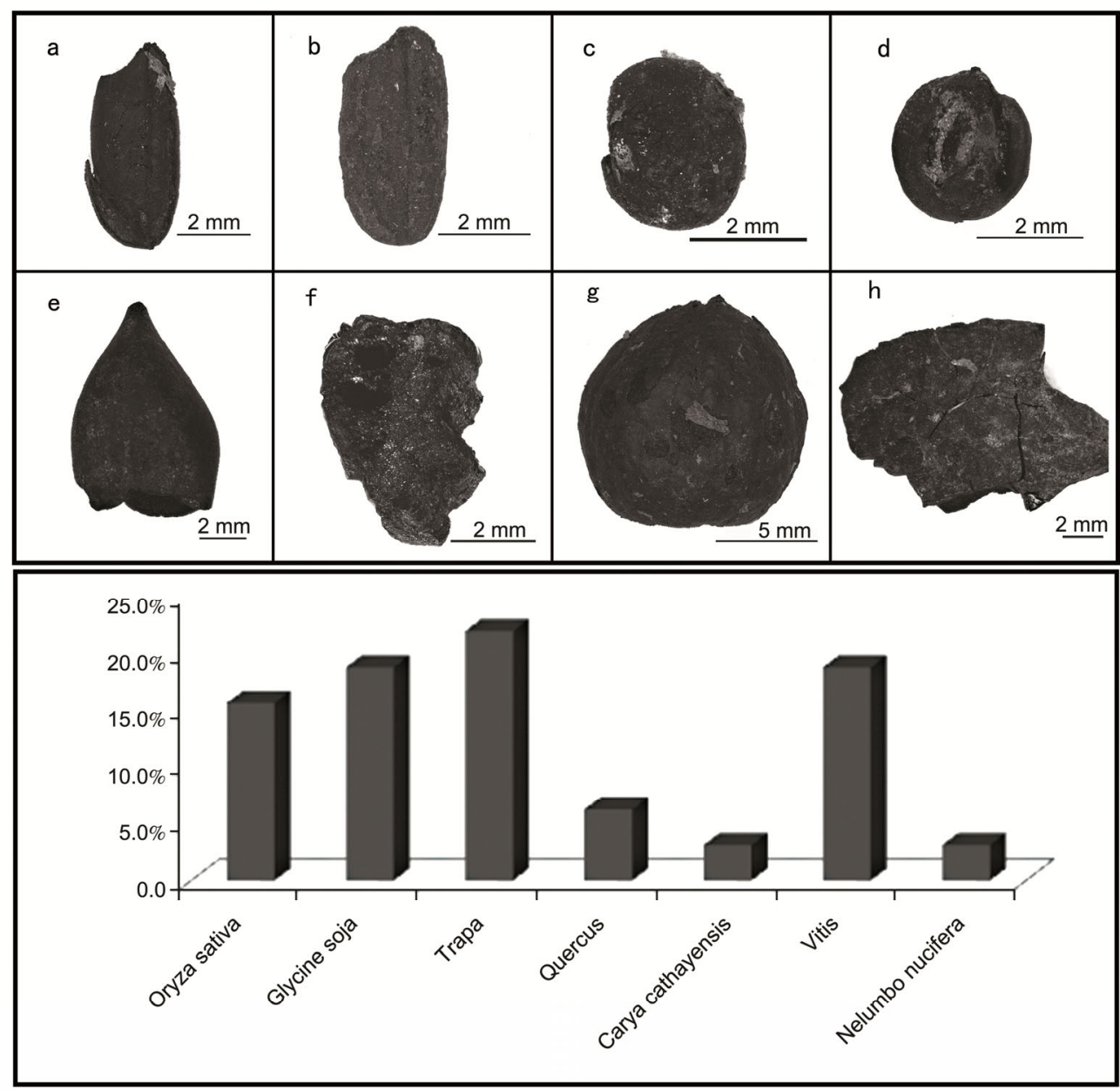

Figure 3 Charred plant remains from the Jiahu site and their occurrence frequencies. (a), Setaria italica; (b), Panicum miliaceum; (c), Oryza sativa; (d), Glycine soja; (e), Armeniaca; (f), Quercus; (g), Diospyros; (h), Setaria.

such as Setaria and Digitaria. Statistical analysis indicated that the occurrence frequency of rice was the highest, followed by foxtail millet, while the lowest was that of broomcorn millet.

\section{Discussion}

The eight sites studied in this paper provided the ideal materials on which to base an analysis of the characteristics and regional differences of early agriculture, covering four main phases of Neolithic culture in the upper and middle HRV. On the basis of the archaeobotanical data from the eight sites, the emergence and development of Neolithic early agriculture in the upper and middle HRV are discussed below.

\subsection{The gestation of early agriculture during the early Neolithic in the upper HRV}

The early Neolithic sites such as Lingjin and Lijiagou are located in the upper HRV (Wang et al., 2011; Li et al., 2014), However, no sites at this period have been found in the middle HRV. In this study, starch grain analysis was carried out on stone tools and pottery sherds unearthed from the fifth layer of the Lingjin site. The results show that snakegourd roots, the tribe Triticeae, Coix lacryma-jobi, Sagittaria trifolia and another three inconclusive species were utilized by the ancient population of Lingjin. Together with the recovery of abundant microliths at the site, this indicates that these plants would have been obtained through gathering. So far, there is no evidence of early agriculture in the upper HRV before $11.0 \mathrm{ka} \mathrm{BP}$.

Although no evidence has been reported of early agriculture commencing before $9.0 \mathrm{ka} \mathrm{BP}$ in the upper HRV, rice and millet have been deemed to be domesticated in the middle-lower Yangtze River and the northern part of northern China during this period (Zhao et al., 1998; Lu et al., 2009; Yang et al., 2012; Wu et al., 2014). A large number of plant remains showing the characteristic of domestication and dating back to $9.0 \mathrm{ka} \mathrm{BP}$, as well as some highly developed archaeological cultures, have been discovered at the 


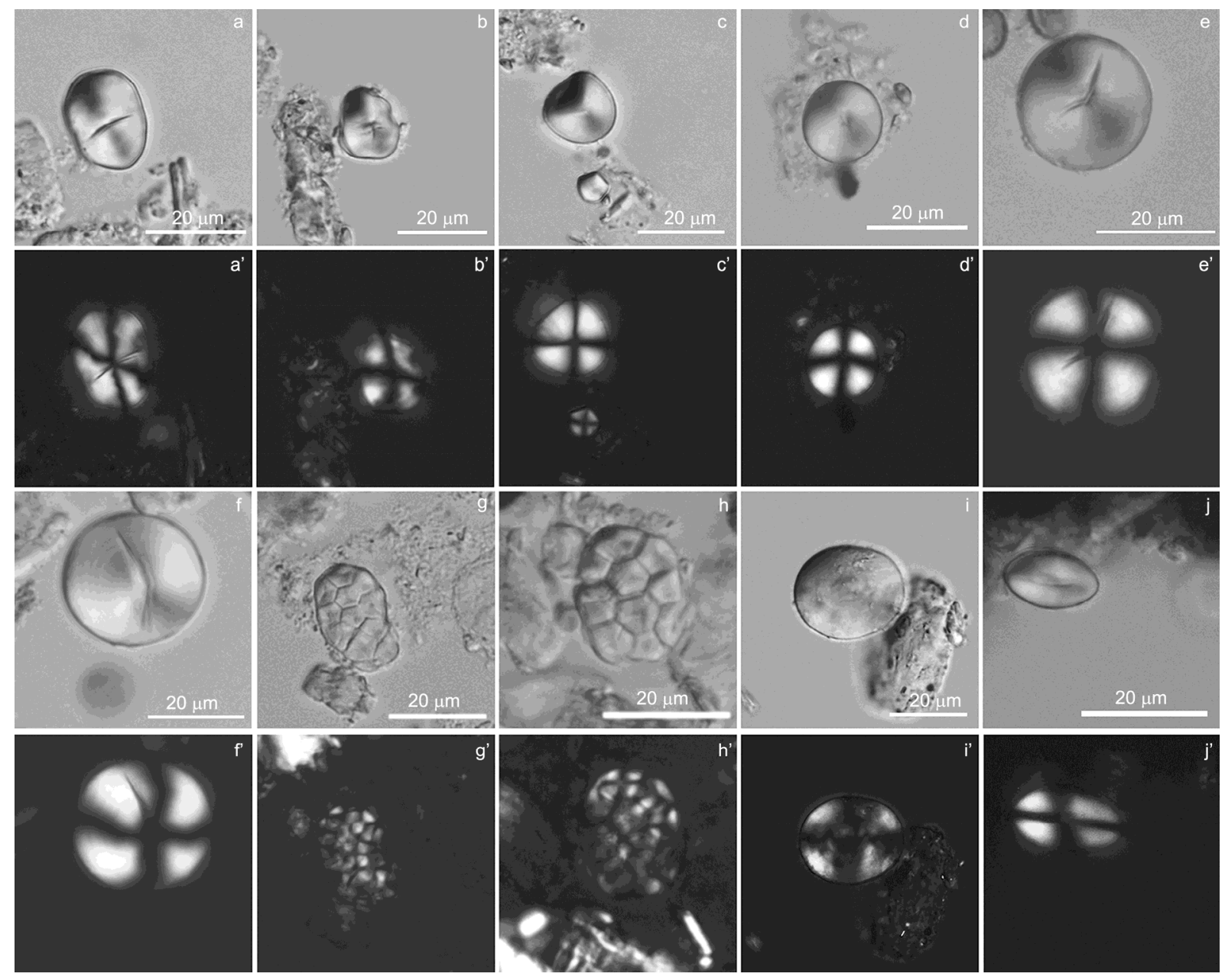

Figure 4 Ancient starches from the Shunshanji site. (a), (a'), (b), (b'), Coix lacryma-jobi; (c), (c'), (d), (d'), Trichosanthes kirilowii; (e), (e'), (f), (f'), unidentified species; $(\mathrm{g}),\left(\mathrm{g}^{\prime}\right),(\mathrm{h}),\left(\mathrm{h}^{\prime}\right)$, Oryza sativa; $(\mathrm{i}),\left(\mathrm{i}^{\prime}\right),(\mathrm{j}),\left(\mathrm{j}^{\prime}\right)$, Triticeae.

Jiahu site in the upper HRV (Henan Provincial Institute of Cultural Relics and Archaeology, 1999). Thus, it is possible that the population of the upper HRV started to cultivate some plants before $9.0 \mathrm{ka} \mathrm{BP}$.

\subsection{The emergence of mixed farming in the upper HRV and the development of rice farming in the middle HRV during the middle Neolithic}

The Jiahu Culture and Peiligang Culture are two representative middle Neolithic cultures in the upper HRV. In the past few decades, abundant carbonized plant remains, including foxtail millet, stones of Armeniacamume and Ziziphusjujuba, and shells of Caryacathayensis and Quercus, have been recovered at many sites of these two cultures (No. 1 Team of Archaeology Institute of CASS, 1984; Wang, 1984; Henan Provincial Institute of Cultural Relics and Archaeology, 1987, 1995). Recently, residue analysis at the Peiligang and Tanghu sites has revealed that the plant species utilized by ancient populations included rice, foxtail millet, broomcorn millet, Quercus, Triticeae, Coix lacry- ma-jobi, Vigna, Chinese yams (Dioscorea opposita), Trapa water chestnut and lotus roots (Nelumbo nucifera) (Liu et al., 2010; Zhang et al., 2011; Zhang et al., 2012; Yang et al., 2015). This archaeobotanical evidence suggests that ancient populations of the upper HRV obtained plant food through both gathering and farming during the middle Neolithic. Notably, phytolith evidence from the Tanghusite proves that mixed farming of rice and millet was already taking place during the middle-late stage of the Peiligang Culture (Zhang et al., 2012).

Jiahu (9.0-7.5 ka BP) was one of the most developed sites in the upper HRV during the middle Neolithic, and eight seasons of excavation have been carried out there since 1983. One of the most important findings here is that the domestication of rice dates to 9000 years ago, which is the earliest record of rice farming in the HRV (Henan Provincial Institute of Cultural Relics and Archaeology, 1999, 2015). In 2001, flotation analyses were carried out at Jiahu, and plentiful charred plant remains were found from rice, Quercus, wild soybean (Glycine soja), Vitis, lotus roots, Trapa and other nuts, as well as Poaceae, Polygonum, 

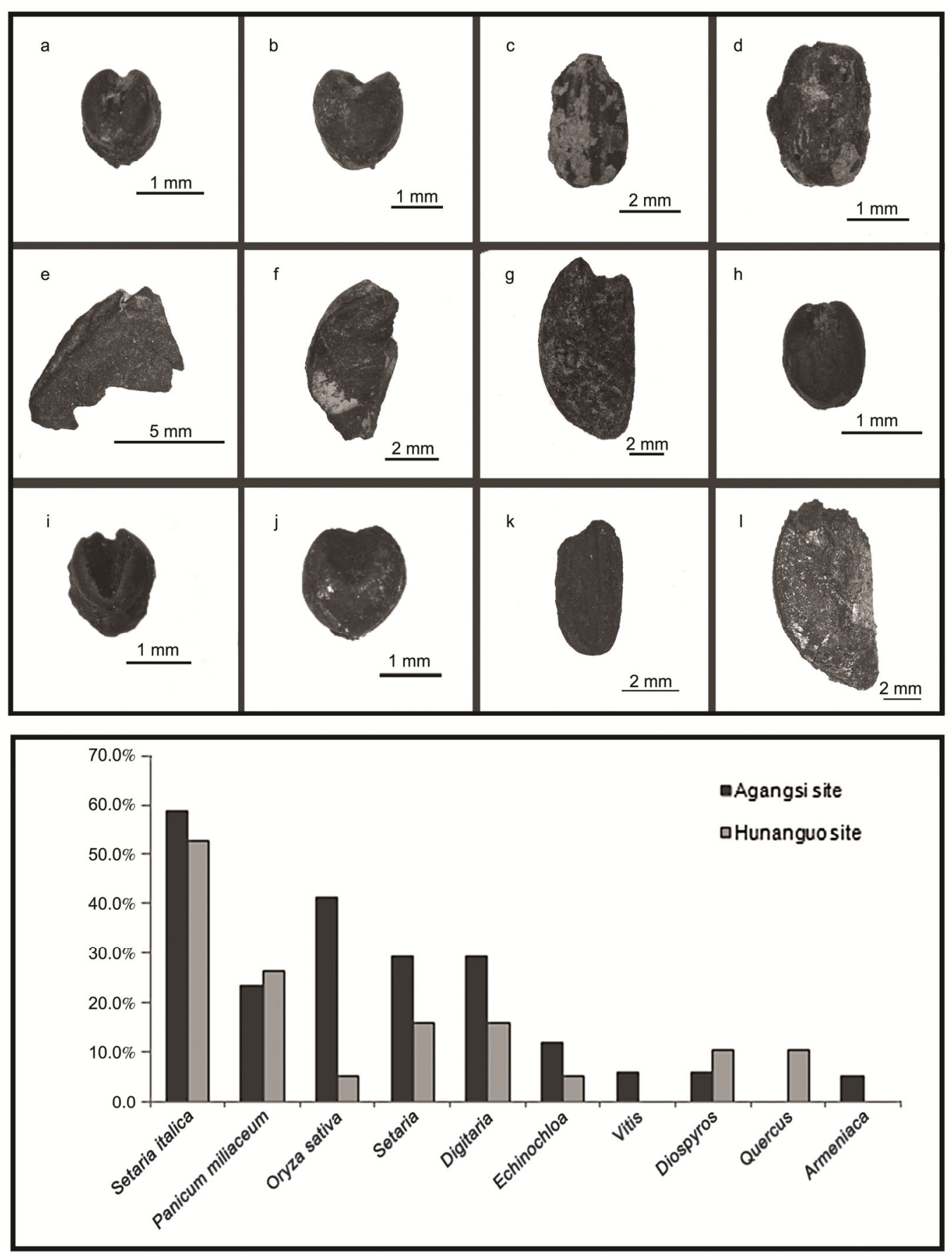

Figure 5 Charred plant remains from the Hunanguo and Agangsi sites and their occurrence frequencies. Charred plant remains from Hunanguo site: (a), Setaria italica; (b), Panicum miliaceum; (c), Oryza sativa; (d), Glycine soja; (e), Armeniaca; (f), Quercus; (g), Diospyros; (h), Setaria. Charred plant remains from Agangsi site: (i), Setaria italica; (j), Panicum miliaceum; (k), Oryza sativa; (1), Quercus.

Chenopodium, Compositae, Cyperaceae, Abutilonaviecnnae Gaerner and Broussonetia papyrifera. The quantitative analysis suggests that the Jiahu people obtained plant food mainly by gathering rather than by rice farming (Zhao and Zhang, 2009). As part of the present study, a flotation analysis was again conducted during the excavation in 2013, and more than 6300 charred plant remains were found, including rice, wild soybeans, Vitis, Trapa, Quercus, lotus roots, Carya cathayensis, and some weedy seeds such as Chenopodiaceae, Amaranthaceae and Portulacaceae. The results of the flotation and occurrence frequency analyses indicate that rice was the only crop cultivated at the Jiahu site and that gathering was still the dominant way for the population there to obtain their plant foods.

The middle Neolithic culture in the middle area of the HRV is represented by the Shunshanji Culture and the 

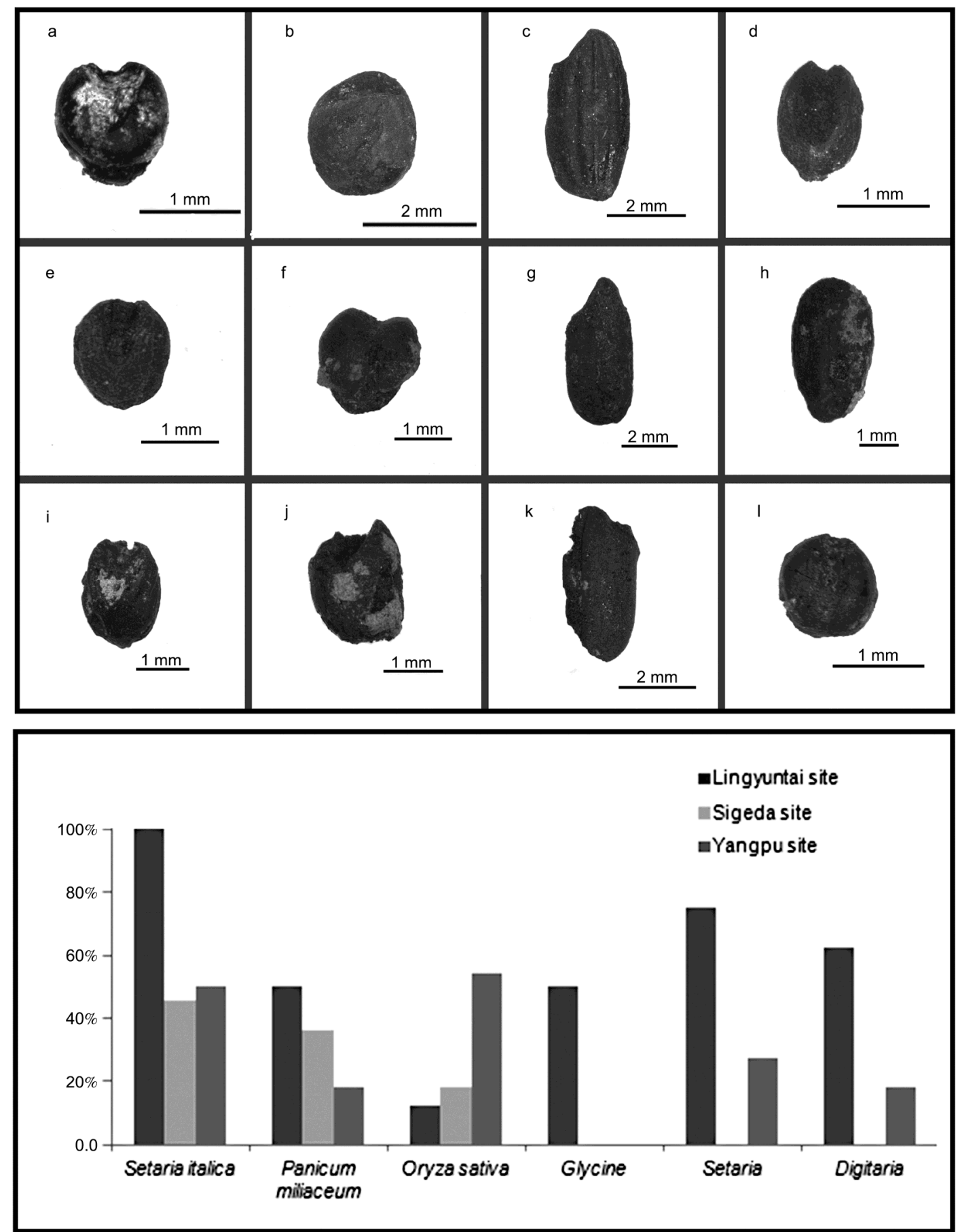

Figure 6 Charred plant remains from the Yangpu, Lingyuntai and Sigeda sites and their occurrence frequencies. Charred plant remains from Yangpu site: (a), Setaria italica; (b), Panicum miliaceum; (c), Oryza sativa; (d), Setaria. Charred plant remains from Lingyuntai site: (e), Setaria italica; (f), Panicum miliaceum; (g), Oryza sativa; (h), Glycine. Charred plant remains from Sigeda site: (i), Setaria italica; (j), Panicum miliaceum; (k), Oryza sativa; (1), Echinochloa.

Shuangdun Culture (Anhui Provincial Institute of Culture Relics and Archaeology, 2008; Lin et al., 2014). Charred rice was found in different phases at the Shunshanji site (8.5-7.0 ka BP), which is the representative site of the Shunshanji Culture (Lin et al., 2014). In the present study, ancient starch grains originating from Coix lacryma-jobi,
Triticeae, Oryza sativa, Trichosanthes kirilowii and one inconclusive species were recovered from the surfaces of eight stone tools and ten pottery shards unearthed from the Shunshanji site. These findings suggest that rice farming was one of the ways for Shunshanji people to obtain plant food. However, in contrast to the sites of the Peiligang Cul- 
ture located in the upper HRV, no millet remains were found at Shunshanji. These results reveal that the ancient population of the middle HRV carried out rice farming rather than mixed farming of rice and millet during the middle Neolithic.

Archaeological sites belonging to the Shuangdun Culture (7.3-6.9 ka BP) are mainly distributed on the north side of the Huai River in Anhui Province and are represented by the Shuangdun, Xiaosungang and Shishanzi sites (Anhui Provincial Institute of Archaeology, 2008). The Shuangdun site was excavated in the 1990s. Zhang et al. (2004) found some impressions of rice husks in pieces of burnt clay gathered at the site. Analysis of starch grains recovered from different types of ground stone tools from the Shuangdun and Shishanzi sites showed remains of rice, Coix lacryma-jobi, Triticeae, lotus roots (Nelumbo nucufera), lotus(Nelumbo nucufera), Dioscorea opposita, Vigna, Avena and some unknown species of Gramineae (Dong, 2013; Dong et al., 2014). Flotation analysis was also carried out at the Xiaosungang site, and plentiful charred plant remains from rice, Trapa, Quercus, Vitis, Diospyros, Ziziphus, Amygdalus, and Armeniacamume were found (Cheng et al., 2016). These findings from Shuangdun, Shishanzi and Xiaosungang demonstrate that rice was the only crop. That is, early agriculture at these sites was single rice farming during this period, like that of the Shunshanji Culture. However, occurrence frequency analysis of the charred plants from the Xiaosungang site shows that the local people of the Shuangdun Culture relied mainly on gathering rather than rice faming in the middle $\mathrm{HRV}$ at that time.

Based on the above archaeobotanical data, it is easy to see that some identical features of early agriculture are shared by the upper and middle HRV during the middle Neolithic. The ancient populations of the upper and middle HRV obtained plant foods not only through farming but also by gathering, although, as can be seen from the occurrence frequency of the plant remains, gathering actually provided more plant foods than farming. However, there were some regional differences in early agriculture between these two areas, with the agricultural mode of the Peiligang Culture distributed in the northern part of the upper HRV being characterized by mixed farming of rice and millet, while rice farming was the single agricultural system of the Jiahu Culture in the southern part of the upper HRV and the Shunshanji Culture and Shuangdun Culture in the middle HRV.

\subsection{Rapid development of mixed farming of rice and millet in the upper HRV during the late Neolithic}

In the upper HRV, late Neolithic culture is represented by the Dahecun type of the Yangshao Culture. However, in the middle HRV, few sites from the late Neolithic have been found, with their absence possibly being due to climatic reasons (Huang et al., 2005).
In the upper HRV, carbonized rice and foxtail millet were discovered at the Dahecun site, the representative site of the Yangshao Culture. This finding indicates that the Dahecun population still relied on mixed farming of rice and millet during the late Neolithic (Ren, 2005). Recently, carbonized plant remains from foxtail millet, broomcorn millet, rice, Ziziphusjujuba, Amygdaluspersica, Vitis vinifera, Crataeguspinnatifida and Armeniaca vulgaris, as well as plentiful weedy seeds, have been found at some sites of the Yangshao Culture. This plant assemblage indicates that farming and gathering were still the two main routes for the ancient population of the Yangshao Culture to obtain plant food. The results of quantitative analysis of these plant remains indicate that the occurrence frequency of crops was much higher than that of other species, with foxtail millet accounting for the largest proportion of all crops (Qin et al., 2010). In the present study, flotation analyses were carried out at the Agangsi and Hunanguo sites of the Yangshao Culture. The results show that the plant assemblage included abundant crops such as foxtail millet, broomcorn millet, rice and weedy seeds. In addition, a few charred remains such as Vitis, Diospyros and Quercus were also recovered. Among these plant remains, crops, especially foxtail millet, accounted for the largest proportion both in number and in occurrence frequency, with plant remains from gathering being recovered sporadically.

On the basis of the above archaeobotanical data from Yangshao Culture sites, it can be seen that mixed farming of rice and millet was still the main agricultural mode in the upper HRV during the late Neolithic (6.8-5.0 ka BP). The diet of the population at this time was dominated by crops, especially foxtail millet, and the role of gathering in the supply of food was in decline. Overall, mixed farming of rice and millet developed rapidly and became the main source of plant foods for the population of the upper HRV during the late Neolithic.

\subsection{Complete establishment of mixed farming of rice and millet in the upper and middle HRV at the end of the Neolithic}

At the end of the Neolithic (5.0-4.0 ka BP), the representative archaeological cultures were the Gushuihe phase II Culture and the Wangwan III phase Culture in the upper HRV, and the late Dawenkou Culture and the Zaolvtai Culture in the middle HRV.

Archaeobotanical studies have recently been conducted on samples from many late Neolithic sites in the upper HRV. Plentiful crops such as foxtail millet, broomcorn millet, rice and soybean, as well as weedy seeds, were found at many sites in the upper-middle area of the Ying River, although at each site only a few plant remains obtained through gathering were recovered. Quantitative analysis of these plant remains indicates that the main agricultural mode remained mixed farming of rice and millet and that crops oc- 
cupied the dominant position in the human diet in the upper HRV at the end of the Neolithic. Further frequency studies on each crop show that foxtail millet was far more widely cultivated than rice (School of Archaeology and Museology of Peking University, 2007). In addition, a large number of macrofossils from foxtail millet, broomcorn millet, soybean and rice were found at the Wangchenggang site in Dengfeng, with foxtail millet having the highest frequency, followed by broomcorn millet and soybean, while the frequency of rice remains was the lowest (Zhao and Fang, 2007). At the Wadian site in Yuzhou, five kinds of crops were discovered in the late Longshan Culture layer, including foxtail millet, broomcorn millet, rice, Triticum aestivum and soybean. Statistical analysis indicates that foxtail millet also accounted for the largest proportion in both number and frequency (Liu et al., 2010). At the Guchengzhai site, only two kinds of crops, namely foxtail millet and broomcorn millet, were recovered, with the number of foxtail millet remains being much larger than that of broomcorn millet remains (Chen et al., 2012). Notably, evidence from phytolith and pollen analyses at the Yangzhuang site in the southern area of the upper HRV shows that rice cultivation existed in a large area around the site during the early Longshan Culture. Moreover, the local population also started to cultivate Sesamum indicum, Polygonaceae and Phaseolus vulgaris during the late Longshan Culture (Department of Archaeology of Peking University et al., 1998).

The Yuchisi and Yuhui sites are the two representative Neolithic sites in the middle HRV. Flotation analysis was conducted at the Yuchisi site during excavations in 2002. A large number of carbonized plant remains were discovered from the late Dawenkou and Longshan Cultures, including crops such as foxtail millet, broomcorn millet and rice, as well as weedy seeds from Panicoideae. Quantitative analysis of the plant remains indicates that foxtail millet and rice were the dominant crops, equally so for the Longshan Culture, although there were slightly more foxtail millet remains than rice remains from the late Dawenkou Culture. These results show that during the late Dawenkou Culture and the Longshan Culture, the main source of plant foods was provided by agriculture, as characterized by the mixed farming of rice and millet at the Yuchisi site, rather than by gathering (Zhao, 2010).

Some charred rice, foxtail millet and broomcorn millet were recovered from flotation analyses conducted at the Yangpu site in Suzhou City. Quantitative and frequency analyses indicated that rice accounted for the largest proportion, followed successively by foxtail millet and broomcorn millet. Furthermore, both rice and foxtail millet were also found at the Yuhui site of the late Longshan Culture, but unfortunately further studies were not carried out, owing to the small number of grains recovered (Yin, 2013).

Above all, mixed farming of rice and millet appeared in both the upper and middle HRV at the end of the Neolithic (5.0-4.0 ka BP). As determined by quantitative and fre- quency analyses, rice, foxtail millet and broomcorn millet occupied the main positions among the plant remains, although some weedy seeds were also found, but plant remains attributable to gathering were basically absent. Thus, it seems that agriculture had established a dominant position by the end of the Neolithic. Mixed farming of rice and millet appeared in both the upper and middle HRV, but there were some regional differences between different regions with regard to the number and frequency of plant remains as a whole. In the upper HRV, millet was more widely cultivated at the Dengfen and Yuzhou sites, located in the northern part of the upper HRV, but rice farming was more common at the Zhumadian site in the southern part of the upper HRV. However, in the middle HRV, rice and millet farming were equal components in the diet of the population at the Yuchisi site in the western part, while rice was more commonly cultivated at the Yangpu site in the eastern part. These regional differences in the agricultural system might be related to variations inhydrothermal conditions in the different regions. However, the relationship between the agricultural differences and environmental and climatic changes needs further study, owing to the absence of highresolution climatic records for the Holocene.

\subsection{Regional differences in the agriculture system be- tween the upper and middle HRV}

From its origin and during its later development, the mixed farming of rice and millet exhibited differences beween the upper and middle HRV.

Based on new and previously obtained archaeobotanical data, mixed farming of rice and millet first appeared in the upper HRV during the middle Neolithic and lasted until the end of the Neolithic, with early agriculture replacing gathering as the main source of plant foods in the subsistence economy from the late Neolithic (6.8 ka BP). Moreover, it is noteworthy that foxtail and broomcorn millet were more significant than rice at the high latitude of the upper HRV, while rice provided a higher proportion of the diet at the lower latitude of the upper HRV. Nevertheless, in contrast to the upper HRV, in the middle HRV, rice farming was the only agricultural economy during the middle Neolithic. So far, the earliest evidence for mixed farming is from the late Neolithic, with the proportion of rice being similar to or slightly higher than that of millet. However, because of a lack of systematic archaeobotanical analysis and high-resolution climatic records for these regions, some open questions remain about the transformation process and the motivation for the shift from single rice farming to mixed farming.

\section{Conclusions}

Early agriculture in China originated in the early Holocene 
at about $11.5 \mathrm{ka}$ BP and then gradually developed and grew to maturity, promoting the formation of agricultural society and the origin of Chinese Civilization. The upper and middle HRV, located in the transitional zone of climate, culture and agriculture in eastern China, is the core area for the formation of early Chinese Civilization. Mixed farming of rice and millet is an important agricultural mode in these regions. The study described in this paper shows that mixed farming of rice and millet first appeared at least 8000 years ago in the upper HRV. The agricultural system then developed quite rapidly during the late Neolithic and became the main subsistence economy at the end of the Neolithic. However, the emergence and development of agriculture in the middle HRV is obviously different from that in the upper HRV. Rice farming was the only agricultural system during the middle Neolithic, and lasted until the end of the Neolithic, when mixed farming appeared in the middle HRV. Furthermore, although mixed farming appeared in both the upper and middle HRV during the end of the Neolithic, the roles of rice, foxtail millet and broomcorn millet in the subsistence economy were not the same. In general, millet was more widely cultivated than rice in the upper HRV, but rice occupied the same or a slightly more prominent position in the middle HRV at the end of the Neolithic. Nevertheless, it should be pointed out that systematic archaeobotanical analysis and high-resolution climatic records for these regions are still lacking. More work is needed to completely understand the transformation process and the motivation for the shift from single rice farming to mixed farming, as well as the relationship between regional differences and environmental and climatic changes.

Acknowledgements This work was supported by the Strategic Priority Research Program of the Chinese Academy of Sciences (Grant No. XDA05130503), National Basic Research Program of China (Grant No. 2015CB953802), the National Natural Science Foundation of China (Grant Nos. 41472148 \& 41502164) and the Philosophy and Social Science Planning Project of the Ministry of Education (Grant No. 15YJA780003).

\section{References}

Anhui Provincial Institute of Culture Relics and Archaeology, Bengbu Municipal Museum. 2008. Excavation Report on Neolithic SiteShuangdun, Bengbu City (in Chinese). Beijing: Science Press. 684

Bar-Yosef O. 2011. Climatic fluctuations and early farming in West and East Asia. Current Anthropol, 52 (Suppl. 4): 175-193

Chen W W, Zhang J Z, Cai Q F. 2012. Analysis of the plant macro-remains excavated from Guchengzhai walled city, Xinmi, Henan Province (in Chinese). Huaxia Archaeol, (1): 54-62

Cheng Z J, Yang Y Z, Zhang J Z, Fang F, Yu J, Chen B B, Chen C F, Zhang H, Gong X C. 2016. Research on charred plant remains from the Xiaosungang site in Huainan city, Anhui Province (in Chinese). Quat Sci, 36: 302-311

Childe V G. 1951. Man Makes Himself. New York : New American Library. 191

Department of archeology in Peking University, Zhumadian Municipal Institution of Cultural Relics Protection. 1998. Zhumadian YangzhuangCultural Relics and Environmental Information in the Upper Huai River During the Middle Holocene (in Chinese). Beijing: Science Press. 91
Dong Z. 2013. Analysis of starch grains on the surface of stone artifacts from Shuangdun and Shishanzi sites. Master Dissertatios (in Chinese). Hefei: University of Science and Technology of China. 66

Dong Z, Zhang J Z, Yang Y Z, Yao L, Li W Y, Jia Q Y. 2014. Starch grain analysis reveals the utilization of plant food resources at Shishanzi site,Suixi County, Anhui Province (in Chinese). Quat Sci, 34: 114-125

Gao G R. 2005. The academic signification of prehistoric culture sequence in Huai River area (in Chinese). J Zhengzhou Univ-Philosophy Soc Sci Ed, 38: 5-7

Ge W, Liu L, Jin Z Y. 2010. Morphological analyses on starch granules of five grass species and their significance for archaeology (in Chinese). Quat Sci, 30: 377-384

Guan G Q. 2000. Identification of Weed Seeds (in Chinese). Beijing: Science Press. 358

Guo Q X. 1998. Identification of Weed Seeds with Colored Pictures (in Chinese). Beijing: China Agriculture Press. 176

Henan Provincial Institute of Cultural Relics and Archaeology. 1987. The excavation report of Shigu site, Changge County (in Chinese). Huaxia Archaeol, (1): 3-125

Henan Provincial Institute of Cultural Relics and Archaeology. 1995. The Shuiquan site of Peiligang culture, Jiaxian, Henan Province (in Chinese). Acta Archaeol Sin, (1): 39-77

Henan Provincial Institute of Cultural Relics and Archaeology. 1999. Jiahu in Wuyang County (in Chinese). Beijing: Science Press. 883-896

Henan Provincial Institute of Cultural Relics and Archaeology, Department for the History of Science and Scientific Archaeology in University of Science and technology of China. 2015. Jiahu in Wuyang County II (in Chinese). Beijing: Science Press. 743

Huang R, Zhu C, Zheng C G. 2005. Distribution of Neolithic sites and environmental change in Huaihe River Basin, Anhui Province (in Chinese). Acta Geograph Sin, 60: 742-750

Li Z Y, L Y N, Kato Shinji. 2014. Observations of microblade core technologies from level 5 of the Xuchang Man site, Lingjing (in Chinese). Acta Anthropolog Sin, 33: 285-303

Lin L G, Gan H Y, Yan L. 2014. The site report of the Shunshanji in Sihong, Jiangsu (in Chinese). Acta Archaeol Sin, (4): 519-562

Liu L, Field J, Fullagar R, Bestel S, Chen X C, Ma X L. 2010. What did grinding stones grind? New light on Early Neolithic subsistence economy in the Middle Yellow River Valley, China. Antiquity, 84: 816-833

Liu L, Bestel S, Shi J, Song Y, Chen X. 2013. Paleolithic human exploitation of plant foods during the last glacial maximum in North China. Proc Natl Acad Sci USA, 110: 5380-5385

Liu L, Ma S, Cui J. 2014b. Identification of starch granules using a two-step identification method. J Archaeol Sci, 52: 421-427

Liu L, Chen X C, Shi J M. 2014a. Use-wear and residue analysis on grinding stones from the site of Niubizi in Wuxian, Shanxi, China (in Chinese). Archaeol Cultural Relics, 3: 109-118

Lu H Y, Zhang J P, Wu N Q, Liu K, Xu D K, Li Q. 2009. Phytoliths analysis for the discrimination of foxtail millet (Setaria italica) and common millet (Panicum miliaceum). PLoS One, 4: e4448

Luan F S. 2005. The prehistoric cultural interaction and differences between the eastern and the western basins of Huai River (in Chinese). J Zhengzhou Univ, 38: 10-12

Meteorological Bureau of Anhui Province. 1983. Climate of Anhui Province (in Chinese). Hefei: Anhui Science and Technology Publishing House. 122-135

Meteorological Bureau of Henan Province. 1980. Climate of Anhui Province (in Chinese). Zhengzhou: Henan People Publishing House. 121-127

No.1 Team of Institute of Archaeology of CASS. 1984. The excavation report of Peiligang site in 1979 (in Chinese). Acta Archaeol Sin, (1): 23-52

Perry L, Michael Quigg J. 2011. Starch remains and stone boiling in the Texas Panhandle Part II: Identifying Wildrye (Elymus spp.). Plains Anthropol, 56: 109-119

Piperno D R, Weiss E, Holst I, Nadel D. 2004. Processing of wild cereal grains in the Upper Palaeolithic revealed by starch grain analysis. Nature, 430: 670-673

Qin L, Dorian Q F, Zhang H. 2010. Modelling wild food resource catchments amongst early farming: Case studies from the Lower Yangtze 
and Central China (in Chinese). Quat Sci, 30: 246-261

Ren S N. 2005. The occurrence and development of the Pre-historical agriculture in China (in Chinese). Academic Exploration, (6): 110-123

School of Archaeology and Museology of Peking University. 2007. The preliminary archaeobotanical report of investigating the upper and middle Ying Valley. In: School of Archaeology and Museology of Peking University, Henan Provincial Institute of Culture Relics and Archaeology. Archaeological discovery and research at the Wangchenggang site in Dengfeng: 2002-2005 (in Chinese). Zhengzhou: Elephant Press. 916-942

Shida N, Marehide I ,Tadashi M. 2004. Seeds of Wild Plants in Japan (in Chinese). Sendai: Tohoku University Press. 261

Torrence R, Barton H. 2006. Ancient Starch Research. Walnut Creek: Left Coast Press. 256

Wan Z W, Yang X Y, Ge Q S, Jiang M. 2011. Morphological characteristic of starch grains of root and tuber plants in south China (in Chinese). Quat Sci, 31: 736-745

Wang J H. 1984. The charred foxtail millets found from Shawoli site, Xinzheng city (in Chinese). Agricul Archaeol, (2): 276

Wang Y P, Zhang S L, He J N, Wang S Z, Zhao J F, Qu T L, Wang J Y, Gao X X. 2011. The excavation of the Lijiagou site in Xinmi city, Henan (in Chinese). Archaeology, (4): 3-9

Wang Z L, Wu J A. 1998. Analysis of phytoliths and discussion on the characteristics of the prehistoric agricultural economy of he Yuchisi site (in Chinese). Archaeology, (4): 87-93

Wei C X, Zhang J, Zhou W, Chen Y, Liu Q. 2008. Degradation of amyloplast envelope and discussion on the concept of compound starch granule in rice endosperm (in Chinese). Chin J Rice Sci, 22: 377-384

Wu Y, Jiang L P, Zheng Y F, Wang C S, Zhao Z J. 2014. Morphological trend analysis of rice phytolith during the early Neolithic in the Lower Yangtze. J Archaeol Sci, 49: 326-331

Yan W M. 2000. The Origins of Agriculture and the Rise of Civilization (in Chinese). Beijing: Science Press. 388

Yang X, Kong Z C, Liu C J, Ge Q S. 2010. Morphological characteristics of starch grains of millets and their wild relatives in north China (in Chinese). Quat Sci, 30: 364-371

Yang X Y, Kong Z C, Liu C J, Ge Q S. 2009. Morphological characteris- tics of starch grains of nuts in north China (in Chinese). Quat Sci, 29: $153-158$

Yang X, Wan Z, Perry L, Lu H, Wang Q, Zhao C, Li J, Xie F, Yu J, Cui T, Wang T, Li M, Ge Q. 2012. Early millet use in northern China. Proc Natl Acad Sci USA, 109: 3726-3730

Yang X Y, Perry L. 2013. Identification of ancient starch grains from the tribe Triticeae in the North China Plain. J Archaeol Sci, 40: 3170-3177

Yang Y Z, Li W Y, LinY, Cheng Z J, Zhang J Z, Xin Y J. 2015. Plant resources utilization at the Tanghu site during the Peiligang Culture period based on starch grain analysis (in Chinese). Quat Sci, 35: 229-239

Yin D. 2013. Flotation results from the Yuhuicun site. In: Institute of Archaeology, Chinese Academy of Social Sciences, Bengbu Municipal Museum. Yuihuicun Site in Bengbu (in Chinese). Beijing: SciencePress. 250-268

Zhang J P, Lu H Y, Gu W F, Wu N Q, Zhou K S, Hu Y Y, Xin Y J, Wang C. 2012. Early mixed farming of millet and rice 7800 years ago in the middle Yellow River region, China. PLoS One, 7: 1-8

Zhang J Z. 2005. A brief discussion of Neolithic culture in the Huai River area (in Chinese). J Zhengzhou Univ, 38: 7-10

Zhang J Z,Yin R C, Yang Y Z, Kan X H. 2004. A sketch on the relation between prehistoric rice-agriculture and civilization progress in the Huai River valley. In: Center for East Asia Archaeology Research in Shandong University, eds. Eastern Archaeology. Beijing: SciencePress (in Chinese). 198-209

Zhang Y H, Weng Y, Yao L, Zhang J Z, Zhou Y J, Fang F, Cui W. 2011. Identification and analysis of starch granules on the surface of the slabs from the Peiligang Site (in Chinese). Quat Sci, 31: 891-899

Zhao Z J, Pearsall D M, Benfer R A, Piperno D. 1998. Distinguishing rice (Oryza sativa poaceae) from wild Oryza species through phytolith analysis, II Finalized method. Economic Botany, 52: 134-145

Zhao Z J, Fang Y M. 2007. Flotation results from the Wangchenggang Site in Dengfeng (in Chinese). Huaxia Archaeol, (2): 78-89

Zhao Z J, Zhang J Z. 2009. The report of flotation work at the Jiahu site (in Chinese). Archaeology, (8): 84-93

Zhao Z J. 2010. Flotation results from the Yuchisi site in Mengcheng of Anhui Province. In: Zhao Z J, eds. Paleoethnobotany: Theories, Methods and Practice (in Chinese). Beijing: Science Press. 109-119 